\title{
Region innovation and investment development: conceptual theoretical approach and business solutions
}

\author{
D.M. Zozulya ${ }^{1, *}$, and Yu.V. Smolyar ${ }^{1}$ \\ ${ }^{1}$ Don State Technical University, Rostov-on-Don, Russia
}

\begin{abstract}
The article describes essential problems of the region business innovation and investment development under current conditions, issues of crisis restrictions negotiation and innovation-driven economy formation. The relevance of the research is defined by the need of effective tools creation for business innovation and investment development and support, which can be applied, first, to increase efficiency of the region industrial activity, then improve production competitiveness on the innovative basis, overcome existing problems and provide sustainable innovation development in the region. The results of conducted research are represented in the article including region innovation and investment development concept model made up by the authors on the basis of system theoretical approach. The tools of the region innovation development defined in the concept model are briefly reviewed in the article. The most important of them include engineering marketing (marketing of scientific and technical innovations), strategic planning, benchmarking, place marketing and business process modeling.
\end{abstract}

\section{Introduction}

According to the Strategy of innovation-driven development of the Russian Federation, the support of innovative business growth at the regional level is considered as one of state policy priorities that determines the need of innovative business development strategies, techniques, models and programs creation for all country regions. The relevance of the research conducted by the authors is defined by the need of effective tools creation for business innovationinvestment development and support, which can be applied, first, to increase efficiency of the region industrial activity, then improve production competitiveness on the innovative basis, overcome the existing problems and provide the sustainable innovation development in the region [1]. Under current economic conditions taking into account complicated political and economic environment, the pressure of the Western countries sanctions on the Russian economy [2, 3], it becomes obvious that there is the need and possibility of innovative business problems solution to accelerate the national economy growth as a whole.

\section{Problem status and research scientific novelty}

The scientific challenge of the conducted research concludes in the need of conceptual approaches, applied models and techniques formulation for the region innovation entrepreneurship development. By now, a number of articles, scientific conference works and theses are published concerning the issues of business innovation and investment development including the regional aspect. The authors have studied the papers of A.A. Dmitriev, V.A. Moiseev, A.K. Klyuev, V.V. Kozyirev, M.V. Charaeva, T.P. Lyubanova, A.Y. Polezhaeva, D.P. Zimin, A.G. Michaylov, E.M. Kozlova, A.G. Ivasenko, Y.I. Nikonova, E.E. Sklyarova, O.N. Kolomyits, V. Blagoev, K. Grenroos, P. Drucker, P. Kotler, J. Culliton, T. Levitt, P. Mazur, J. Scott, J. A. Traut, H. Hershtein, R. Chapman, E.P. Golubkov, Z.K. Okeanova, Y.V. Pashkus, B.A. Soloviev, B.V. Srebnik, O.A. Tretiyak and other scientists in the field of marketing, innovation development, region innovation development, marketing mix, business modeling, innovation infrastructure and strategic planning.

At the same time, it is worth mentioning that specified researches fell short of some theoretical and practical aspects of marketing in the context of innovation business development enabling to evolve competitive strength management functions on the innovative basis for sustainable innovative and investment development of the region in the market environment.

The scientific novelty of the conducted research concludes in the region innovation entrepreneurship development concept model formulation with the use of system and complex approaches and involvement of strategic planning, engineering marketing and place marketing tools.

The practical scholarly importance of the research is expressed in the possibility of concept model implementation in business environment for 
achievement of sustainable innovation and investment development of region business.

\section{Region innovation and investment development concept model}

It is commonly known that innovation activity is one of the major factors promoting development of many other activity areas. Fast development of the nextgeneration technologies justifies the trends of innovation-based economy formation in the developed countries of the world as well as in Russia [4]. However, as we know, a number of barriers and difficulties appear on the way of innovation business development in Russian regions, which in the opinion of the authors include the following:

a) innovation and investment infrastructure problems, including industrial, organizational, personnel, financial, information and international infrastructure [5];

b) the shortage of professional, properly technically, economically and intellectually trained personnel for innovative technological business dealing in conditions of human capital role increase [6];

c) problems of marketing orientation and commercialization of the developed technical products, operations, technologies [7, 8, 9].

Formation of the innovation-driven economy seems impossible without solution of specified problems. On the ground of the research conducted by the authors, study of the available scientific backup and synthesis of a number of hypotheses, the concept model of the region innovation and investment development was made. The model is shown in the figure 1 .

Concept model demonstrates the following basic elements of the region innovation development, which are capable to promote the transition to innovationdriven economy upon condition of their cumulative activity:

a) legislative support of the innovation activity not only in the field of quality regulatory support of copyright protection, but also legal framework development for innovation business;

b) innovation activity public awareness campaign in the region with the use of mass media, exhibitions, scientific shows and so on;

c) development of the innovation-oriented culture in the region;

d) operation of the region innovation and investment infrastructure;

e) use of the corresponding tools and innovation development technologies by the innovation enterprises;

f) achievement of the results of efficient innovation development including initiation of new productions, region schools of thought development, support of science, education and business effective interaction, foundation of the region integrated innovation cluster, innovations commercialization support, etc.

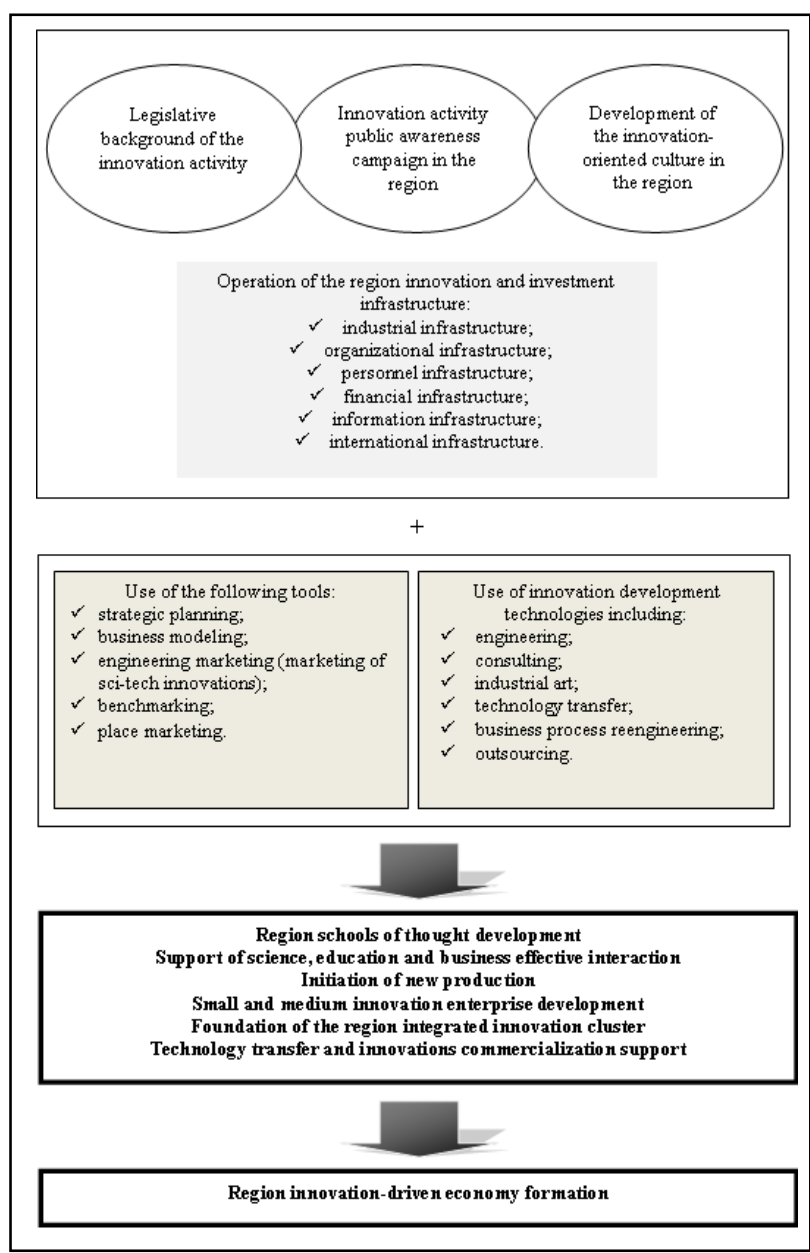

Fig. 1. Region innovationd investment development concept model.

The first block of the region innovation and investment development concept model is presented by mainly state level activity. It should be emphasized that creation and development of innovative and investment infrastructure including all of its parts plays an important role in model possible realization. The industrial infrastructure assumes providing branches and enterprises with technological capabilities, equipment, production capacities, platforms, communications, transport communications, etc. Organizational infrastructure component consists of a number of organizations rendering various services to small and medium innovation business in the field of consulting, communications, premises and equipment rent, initial funding, transport. In general such organizations include business incubators, science and technology parks, technopolises, engineering companies, consulting agencies and so forth. The financial infrastructure is presented by funding investment opportunities, which can be provided to innovation business.

As one of the main problems of innovation and investment development is the lack of funding, credits and investments, it seems necessary to develop specific forms of innovative projects financial support, for example, venture financing, foundation of securities market specially for startup small and medium innovation business with favorable conditions of financial resources raising, organization of independent financial/investment pools for 
innovation business and so forth. The clusterisation of innovative activity is also one of options of a number of organizational and financial problems solution by means of small and medium innovation enterprises integration in innovation clusters, which represent goal-oriented group of companies, operating on the basis of the scientific knowledge production and highly qualified specialists training centers [10]. At the moment, the activity of twenty five Russian clusters covers six primary industries, including nuclear and radiation technologies, shipbuilding, flying and space vehicles production, pharmaceuticals, biological technologies and medical industry, new materials, chemistry and petroleum chemistry, information technologies and electronics.

The critical problem of personnel infrastructure in the innovation field consists in the shortage of professional, properly technically, economically and intellectually trained personnel for innovation business dealing. This problem shows the need of the system well-balanced education when the student can gain knowledge and master skills not only in basic and engineering sciences, but also in the field of economy, management, marketing (engineering marketing), project and risk management, self-introduction and psychology. One of the most important components of innovative business infrastructure is the information part, the development of which plays an important role in creation, promotion and commercialization of innovative products, operations and services. Information infrastructure part has great marketing significance especially for innovation business suffering from promotion and commercialization difficulties and struggling for competitive advantages. The international component of innovation infrastructure is intended to promote international researches, studies and projects, public awareness campaign of innovation business on a global basis, cross-country technology transfer and so on.

The second block of the region innovation and investment development concept model contains the set of tools and innovation development technologies, which are recommended to be used by innovation enterprises to promote their goals achievement. It is important to note that the analysis of enterprises activity of the Southern Federal District of Russia approved the deficiency of the strategic planning viable mechanism for their development. At the same time, planning is necessary for any enterprise even in crisis conditions because it represents the dynamic process allowing to expect and consider external environment changes, and to adjust enterprise production capabilities and limitations for further development and growth.

The procedure of strategic planning is considered to include not only a simple sequence and interrelation of separate stages, but also maintenance of feedback between them and external environment of the enterprise. Every stage has its logic and promotes optimal decision-making in planning field. The first stage of strategic planning process includes strategic situation analysis and predetermines selection of possible strategy depending on the external and internal environment, taking into account main factors influencing enterprise economy. Key success factors are defined on the basis of enterprise strengths and weaknesses analysis. Strategic management areas qualifying enterprise industry are determined at the second planning stage, as well as strategic management centers, which are selected from enterprise production departments focused on one or several strategic management areas. The third stage is dedicated to the assessment of strategic position with the use of market models. The fourth stage is characterized by enterprise business portfolio selection on the ground of strategic management areas analysis. The fifth planning stage includes development of financial plan, balance of income and expenditure making-out, break-even point calculation, profit forecast. Efficiency of financial policy is defined by use of cash flow model. The sixth stage consists in function planning (technical and economic planning). The seventh stage contains definition of key figures of strategic plan as benchmarks of strategic goals achievement. The structure of key figures can vary as well as the planning period. Key figures of strategic plan can include sales volume, market share, fixed assets value, staffing level, payroll budget and so on. The eighth stage assumes control of all other planning stages depending on market changes, results monitoring and plan updating. Thus, enterprise strategic planning process is focused on definition of the global goal and strategy proved by methods and models of strategic analysis, business portfolio selection and implementation with application of technical and economic planning, and on definition of key figures of the strategic plan [11].

Modern enterprise management should be absolutely market-oriented to gain competitive strength and achieve its goals [12], [13]. Therefore, it seems appropriate to use the tools of place marketing and benchmarking as the comparative analysis study of enterprise activity efficiency and indexes of more successful companies [14], for competitive advantages gaining, for survival and adjustment to external conditions, etc.

Engineering marketing (marketing of engineering activity, marketing of scientific and technical innovations) is supposed to be one of the tools promoting enterprises innovation activity increase, achievement of competitive strength and commercialization of innovations [15]. It is the authors' opinion that scientific and technical innovation means the eventual result of innovation activity (of fundamental studies, exploratory research, applied studies, development, experimental works), which is ready for commercialization. According to T. Levitt, a product is not something engineer talks about, but it is something that consumer needs [16]. Engineering marketing is considered to be a new marketing trend developed to increase engineering activity efficiency by means of engineering solutions market orientation provision. Engineering marketing is the innovative and perspective approach developed by Tatiana P. Lyubanova and Daria M. Zozulya [17]. This new approach is based on the theory that under current conditions all employees of enterprises have to make decisions from the standpoint of market philosophy being the generators of scientific-technological progress able to synthesize enterprise engineering capabilities and consumers' needs successfully.

Such tools as enterprise business model and strategy development on the ground of engineering marketing [18], innovation marketing model drawing up [19], planning with the use of engineering marketing mix, psychoheuristic programming for alternative engineering solutions 
evaluation and others are used for engineering marketing practical realization in engineers' professional life.

Specific character of engineering marketing mix 9P (people, product, production, price, place, promotion, public relations, provider, processing) in comparison with other concepts assumes that its tools include engineering capacity and are intended for use by engineers (designers, technicians, developers, researchers and so forth) for the purpose of engineering solutions market orientation maintenance. For instance, the first essential tool "people" (meaning consumer needs satisfaction by engineering solutions) includes such way of impact as customization. Customized product is made for specific consumer. Only engineer is capable to develop and produce customized unique product. In addition, he has to synthesize his technical competence, enterprise capability and results of innovations market research and communication with customers.

Examination of engineering marketing mix tools in their interaction is of great importance. Enterprise resources planning with consideration of consumer needs by means of corresponding software use based on specific needs integration into production planning process may serve as a good example. Assortment and production schedule planning is carried out on the basis of consumers requests placed in enterprise data system of suppliers. As a result, product competitiveness can be increased [20].

Except the described above tools of innovation activity growth the concept model of the region innovation and investment development also contains a number of innovation development technologies including engineering, consulting, technology transfer, outsourcing, business process reengineering, industrial art, which can be efficiently practiced by experts for specific problem solution.

Considered blocks of the concept model should function in efficient mode to achieve the goals of innovation development, which, in turn, provide background for the region innovation-driven economy formation.

\section{Conclusion}

As part of the region innovative and investment development challenges and opportunities research the concept model of the region innovation and investment development was made by the authors. The model is shown and briefly described in the article. Practical realization of the model will promote achievement of innovation development goals, solution of a number of technological business problems and formation of the region innovationdriven economy.

It should be noted that validity of authors' conclusions and research results is confirmed by the application of the following methods and tools: comparison, analysis, synthesis, formalization, statistical methods, economic methods, methods and tools of marketing, engineering marketing, place marketing, Delphi method, business process modeling.

Authors believe that the main task of the follow-up study of this subject consists in the improvement and creation of new tools of innovation business development.

\section{References}

1. D.M. Zozulya, V.G. Lisitsin, P.B. Golivkina, V.S. Milovanova, A.A. Mozgaleva, M.E. Povarova, Koncept, 13, 1856-1860 (2015)

2. Y.S. Toktamysheva, Parameters system used for evaluation of goals achievement of the region social and economic development strategy (Aeterna publishing center, Ufa, 2015)

3. Y.S. Toktamysheva, Vestnik Bashkirskogo universiteta, 20, 142-147 (2015)

4. N.M. Ovanesyan, Problems of current marketing in Russian economy: theory and practice Don state technical university publishing center, (Rostov-onDon, 2014)

5. D.M. Zozulya, Koncept, 4, 1101-1105 (2013)

6. V.P. Kolesov, Knowledge-driven economy (Infra-M publishing center, Moscow, 2008)

7. T.P. Lyubanova, D.M. Zozulya, Vestnik Donskogo gosudarstvennogo technicheskogo universiteta, 10, 4(47), 596-603 (2010)

8. B.A. Soloviev, Marketing (Infra-M publishing center, Moscow, 2007)

9. O.A. Tretiyak, Marketing: new guides of management model (Infra-M publishing center, Moscow, 2009)

10. B. Twiss, Scientific and technical innovations management (Economika publishing center, Moscow, 1989)

11. T.P. Lyubanova, D.M. Zozulya, A.E. Safronov, Modern concepts of scientific studies, 6(15), 50-53 (2015)

12. P. Drucker, Effective management. Business problems and optimal solutions (Fair-Press publishing center, Moscow, 1998)

13. T. Peters, R. Waterman, In search of effective management (experience of the best companies) (Progress publishing center, Moscow, 1986)

14. B.V. Srebnik, Marketing (Vyishaya shkola publishing center, Moscow, 2005)

15. T.P. Lyubanova, D.M. Zozulya, Engineering marketing as a tool of industrial enterprises' development efficiency increase (LAP LAMBERT, Saarbrucken, 2012)

16. T. Levitt, The Marketing Mode. Pathways to Corporate Growth (Irwin, New-York, 1969)

17. D.M. Zozulya, Koncept, 20, 2106-2110 (2014)

18. D.M. Zozulya, Y.N. Denisenko, Science and Education: Agriculture and economics; predprinimatel'stvo; law and governance, 6(49), 43-49 (2014)

19. S.M. Hashin, D.M. Zozulya, A.E. Safronov, Innovation project management (Don state technical university publishing center, Rostov-on-Don, 2013)

20. D.M. Zozulya, V.P. Gacenko, High Tech, 7, 44-49 (2014 